\title{
Internal Migration of Disaster Distressed Women and Driving Forces to Lead Migrant Women into Sex Work: a Qualitative Study Based on Dhaka City, Bangladesh
}

\author{
Zarin Yesmin Chaity ${ }^{1}$, Md. Arifur Rahman ${ }^{2}$ \\ ${ }^{1}$ Lecturer, Dept. of Women and Gender Studies, Begum Rokeya University, Rangpur, Bangladesh \\ ${ }^{2}$ Gender Trainer, Gender Justice \& Diversity Programme, BRAC, Bangladesh
}

\begin{abstract}
The people of Bangladesh are exposed to many types of disasters every year but the impacts of disasters are gendered and fall upon women and men differently. This article aims to explore the driving forces which influence women to migrate after disaster and ultimately lead a section of them to be involved in sex work. Information has been collected using In-depth Interview and FGD tools from 45 female sex workers who were purposively selected. The study documents that the driving forces which have been divided into Push and Pull factors mainly determine their entry into sex work. These do not arise from linear source rather these are multidimensional and interrelated with each others. The respondents have been identified lack of rehabilitation initiatives, lose of house and earning member, poverty, job scarcity, Gender Division of labor, trap of agents, violence and social stigma regarding women's virginity as push factors and better life, job, eradicate violence and poverty, easy access, no investment and immediate benefits of sex work as pull factors. Finally recommendations are given that combined and strategic gendered policies and initiatives are required to stop women being involved into sex work and to rehabilitate them.
\end{abstract}

Key Words: Disaster, Internal Migration, Pull Factor, Push Factor, Sex work

\section{INTRODUCTION}

The research intends to explore the driving forces which lead disaster distressed women to migrate and adopt sex work as profession by a section of internally migrated women. The people of Bangladesh survive struggling with different types of disasters and environmental degradation [1]. Every year disaster uproots people from their settlements, cause unemployment and marginalize people with little resources. This hard situation forces people to relocate shelter, move to less affected areas or migrate to others areas to find shelter and new employment $[2,3]$. The principal victim of disaster and environmental degradation are the most underprivileged people and the majority of these are women. Women are the worst victims of natural disasters compared to men due to their secondary position in society $[4,5]$. Women are faced with greater uncertainties because they find it more difficult to have access to relief and rehabilitation program of the government [6]. Social crime and violence increases against women during or after disaster, even they become victims of rape and social oppression. All these factors increase tendency of disaster distressed women to migrate to others areas and find livelihood opportunities to survive. A related study shows that sometimes they have no alternative way than to choose beggary or prostitution to survive in new place [7]. Another study reveals that the effect of climate change and disaster have driven women in coastal areas in poor countries into dangerous work like prostitution whereas these calamities have caused destruction and reduced their income from farming and fishing [8]. Moreover, in competitive labor market it is more difficult for women to get job than men due to gender division of labor, discrimination and lack of opportunity, skill and experience $[9,10]$. Women do low quality job like domestic servant, garments work, construction work etc. Some even cannot manage these low jobs too and their misery is increased when they are alone without shelter in a new place. Therefore, a section of migrated women engaged with sex work under different circumstances. Many influencing driving forces work as catalyst to draw disaster migrated women into sex work. This research has tried to find and explore those driving forces which push internally migrated women to be involved with sex work as profession.

\section{OBJECTIVE OF THE RESEARCH}

The objective of the research is to explore driving forces that push disaster distressed women to adopt sex work as profession. Sex work is not first choice for women of any situation, though many women are being added to the number of sex worker gradually. This research aims to find the factors which lead disaster distressed women to migrate and join in sex work. 


\section{METHODOLOGY OF THE RESEARCH}

The research is qualitative in nature which intends to explore disaster distressed women's push and pull factors to be involved in sex work. This is an experience based subjective research so qualitative research methodology has been applied to collect descriptive and in depth information from the respondents. Contextually subjectivity helps to ensure strong objectivity in research [11, 12]. The sample people of the study were distressed women who moved into Dhaka and engaged in sex work. Among permanent and floating sex worker, second category sex workers were studied under the study those internally migrated from their native village to Dhaka city. The study analysis is entirely based on primary data collected from the purposively selected respondents. Total 45 respondents participated in data collection process through In-depth interview and FGD. 10 in depth interviews and 3 FGD sessions were conducted to collect data who reported to have engaged in commercial sex occupation. As study area Dhaka, the capital city of Bangladesh has been selected because generally the folk of disaster affected people moved to city areas and Dhaka as capital city is the main target of migrated people to move in [13]. The study was conducted in two areas of Dhaka city; one study area is organization of sex workers 'Durjoy' situated at Shamoli, Dhaka. 'Durjoy' is rights based activist organization of sex workers. Another area is Sohrawardhy Uddan, a park at Shahbag and one of the centers of sex worker especially floating sex workers.

\section{RESULT ANALYSIS: DRIVING FORCES TO ADOPT SEX WORK BY DISASTER DISTRESSED WOMEN}

Disaster and environmental degradation of the country drive huge number of people internally migrate to big cities. As the context of internal migration varies from person to person, the experience and consequence of migration also differs from each other especially between women and men $[14,15]$. This study finds that the women migrate to Dhaka; some of disaster distressed women get involved into sex work due to few influencing factors. The respondents have indentified few driving factors which have been categorized into push and pull factors that lead internally migrated women into sex work. The respondents of this research identified Push factors as those factors which force people to move and pull factors as the factors which encourage people to move. The push and pull factors have been discussed below-

\subsection{Push factors}

\subsubsection{Destruction of residence and resource by disaster}

Disaster causes huge destruction and it has long term affect on people and society. The study findings show that most of the respondents lost their house and resources by disaster. After coping up of a loss of one disaster they fall into another. As a result they can't turn around and they become destitute by losing everything in a disaster. They were poor but disaster made them more poor and vulnerable than before. Due to distraction caused by disaster, lose of house and resources people migrate to Dhaka. Most of the respondents have given their opinion that women migrate more than men after disaster.

One respondent Parvin Begum mentioned the reason behind this by saying that "Men can do any job in village like rickshaw pulling, business, day labor, agriculture and so on. But women's opportunity of work in village is very limited. Women's earning activities are not welcomed in a good way in rural areas and it is more shameful for the women to work in their native village in front of familiar people because of family honor especially when the position of women was good prior to disaster. So they feel more comfortable to come to Dhaka for work where there more opportunity of work and no one will know them what they are doing in Dhaka city."

When in a new place women do not find any way to earn money and desperately seek job to survive they easily get trapped by the sex worker agent and some involve in sex work.

\subsubsection{Death of only earning member}

Women's vulnerability is further increased by the loss of men or male head of household and the women must provide for their family. This situation compels women to be involved in income generating activities and pushes them to migrate. Few respondents said that they had lost their family members during disaster; among them some were their only earning member of the family like father or elder brother. Losing of only earning member drastically changed their family and all of a sudden women have to take family responsibility and become earning member of the family. Most of the respondents were never involved in income generating activities while their earning members were alive. So they had no prior experience and knowledge about labor market. All of the respondents of FGD agreed to this point that in this competitive labor market women have very limited opportunity to income as they are inexperienced and inefficient labor. So they either have to struggle and earn less money spending equal or even more time than men or search such work which does not need prior experience and women have capital or ability to do so. Sex work though unacceptable 
in the society but distressed women who are bound to income for family or her own survival right after terrible situation of family involve in sex work where they do not need any capital, skill or experience.

\subsubsection{Lack of immediate and sufficient rehabilitation initiatives}

Women have less access to resources- social networks and influence, transportation, information, skills (livelihood, swimming, literacy and self protection etc.), control over land and other resources, personal mobility, secure house and employment and control over decision making - that are essential in disaster preparedness, mitigation and rehabilitation. Due to absence of these resources women are tended to face more difficulties to get rehabilitation facilities. According to the respondent's experience rehabilitation initiatives are very important factor to mitigate the amount of loss of disaster and come back to regular life. But the government and other local NGO's fails to meet up the immediate demand of emergency situation of affected people and to take initiatives to rehabilitate disaster distressed people. The relief, medical support and other necessary services are given by the government are very insufficient in regarding to demand. So women fall in more vulnerable and helpless situation. Most of the respondents of FGD and Interview said that the relief they got from government and other organizations were very limited and they hardly got rehabilitation facilities.

Shila Akter, a respondent of FGD said that-

"If government had taken any initiatives immediately, my family never had to become destitute; I didn't have to come in Dhaka and would not be a sex worker to survive."

Women lack rights and access to resources and information which are vital to overcoming challenges of disaster. Women become more helpless in disaster while they do not get immediate and proper rehabilitation.

\subsubsection{Extreme and Immediate poverty}

Poverty has been mentioned as an important driving force by the all of the respondents which pushes them to migrate and chose sex work to survive. Massive loss of property and resources increase poverty rate among disaster affected people. Disaster creates immediate poverty situation and bring disaster affected families down to earth who were solvent prior to disaster. Traditional patriarchal society has many options of job for men. But due to inefficiency women face hardship to find any suitable work to eradicate poverty [16, 17]. Their household liabilities are also increased after disaster. Mentioning poverty as prime force for being sex worker Bithi Begum said that,

"While my parents were killed by my uncle over property dispute, I took shelter in my paternal grandparent home. But two years later my grandparents also died in severe storm. I was 17 years young girl without family, food, shelter and money. Our economic situation was not so bad but disaster had taken away everything from me. So I moved to Dhaka alone for work and by an agent of sex worker involved in sex work."

\subsubsection{Rejection of assistance by relatives}

After disaster usually all families face difficulties more or less. During this hard time many people deny to help or give shelter to other persons or relatives for long time. Two respondents of in-depth interview mentioned that when they had fallen into such hard situation because of disaster their relatives ignored them as they were extra burden and denied to help. One of the respondents shared that because of storm, her family lost home, arable land, trees and other resources. Her only elder brother flew to get rid of this situation. So she has to take the responsibility of her family because her father was physically disabled to work who was the only earning member of her family consisting of 6 members. Many other respondents also mentioned that they did not get any help from their relatives rather rejection and so under compulsion they moved to Dhaka to survive.

\subsubsection{Sexual Division of labor and scarcity of Job opportunity}

Gender Division of labor assigns different roles, responsibilities and tasks to women and men according to their gender identity, not necessarily according to their preference or capabilities (Bhasin, 2000). This is male dominated societal idea that men will do productive work which has economic value. Reproductive responsibility, household work, child rearing, pleasure and care giving works are considered as women's work which have neither recognition nor money value. Society resists women to engage in productive work so they remain unskilled and inexperienced about productive work thus results public private dichotomy in the society. Women are made more vulnerable to disaster through their socially constructed roles and gender division of labor.

Shima Begum, one of FGD respondents shared that -

"There are no working opportunities for women except garments work, parlor work, cooking in hotel or mess or home maid? Most of the women are familiar with these types of work as women usually do these works at their home like cooking, sewing etc. In rural areas we (women) are not allowed to work outside so we cannot get productive working skill which pushes us to do such works that do not require any specialized skill but low quality. So we choose sex work which was only option for us after migrating to Dhaka" 
It is noteworthy here that women have very limited opportunity of work like garments worker, home maid, construction worker which are already have been labeled as feminine job. Society has divided works in so called men type and women type work so when women forced to involve in income generating activities because of disaster they hardly find any work immediately which are their type job. So partially gender division of labor pushes women to migrate and engage in sex work which is pleasure related work.

\subsubsection{Demand of sex work}

Though Sex work, the oldest profession of human history, is not acceptable profession in the society but the strange thing is that the demand of this work has been created by the society. All the respondents agreed that though being unacceptable and prohibited work sex work has huge demand and expanded market in the country as well as worldwide. Continuous growing demand and expansion of sex market increasing the number of sex worker daily though they never wanted to be so. Sex market require young and fresh worker regularly so demand never falls rather increases. To meet up this increasing number of fresh and young girl the supplying sources collect women from different places of the country through different strategies.

One respondent of IDI Parvin said that,

"No one can imagine the extent of sex market from outside and how high the demand of sex worker is. Women especially those who are poor young, vulnerable and destitute are at great risk of being trapped by the agents. Everyday many women are being victim and forced to join in this profession."

So due to growing demand of sex market this prohibited and unacceptable profession exist in the society till now and expanding day by day.

\subsubsection{Trap of Sex worker agents}

The backgrounds of the sex workers coming into sex work were not same but one thing is very common among all the respondents that they were ensnared by sex worker's agent and then become sex worker. No woman came to Dhaka to be sex worker but using the distressed women's vulnerability the sex worker agents spread a snare in the name of helping them and trapped in sex work.

Nuri Begum, an In-depth Interview respondent said that-

"I worked in a garment. A familiar woman said that to work with her sister who has business of sari (one kind of women's dress) and she will give you more money than garment. I went with this lady and trapped in a brothel. Since that day I could not get rid of myself from this profession"

Another respondent Bipasha Begum shared that-

"I came to Dhaka for work after losing everything in disaster. I met with a woman at Sadarghat Launch terminal and she talked me. I trusted her and told her everything about my condition. This women gave her food and said to go with her she will give a home maid job. I went with her but this woman sold me at Narayangong Brothel".

According to the respondents there is huge number of male and female agents roam throughout the country and search for preying. Young girl or migrated women are easy prey as they are new, helpless and in urgent need of work. Agents collect girls deceiving or forcefully and sell them to main agent or owner of Brothel. Once girls are entrapped they do not find any option to way out and imprisoned in sex work for life time. Even though very few can manage to escape but society does no except them and push back her to go to the same profession. Here there is only one way of coming, but no exit even if anyone wants due to lack of social awareness and rehabilitation initiative for them.

\subsubsection{Violence and sexual harassment against women during post disaster period}

Violence against women and security problem are very common in a male dominated society. They have to face different types of violence throughout their life. Women live with fear of harassment and rape, eve teasing and other types of violence. This situation is worsened during or after disaster as violence and social oppression increase against women in the family or society. Women and young girls face sexual harassment in disaster shelters during or after disaster. Some respondents of FGD said they took shelter in disaster shelter during disaster and their experience is no exception of this. Two of the respondents were raped by the local boys or terrorists after disaster. Due to fear of social shame they flew from their society and came to Dhaka to survive but became sex worker being victim of situation. Regarding this one respondent shared that -

"One day I was coming through the road, the local boys took away my "orna" (One kind of piece of cloth used for covering female body), and forcedly brought to nearest silent place and raped me. I had nowhere else to go so I planned to escape from the village. I went to a familiar woman who promised me earlier to give a job in Dhaka. I did not know it was a trap and I had no other way rather being a sex work." 


\subsubsection{Social stigma related with women's sexuality and virginity}

The society adds high value on women's virginity and chastity. If woman lost her virginity even if being forced, she is never accepted in society and cannot come back into normal life because in a patriarchal society rape victim is regarded as culprit and the rapist live normal life in society. The respondents who were rape victim they never returned to their home because their society even family will not accept them. The other girls who were trapped and brought into brothel, once they engaged in sex work for the first time in brothel then they had no other way except to choose sex work because they knew that they have no place in the society. They said that, some girls tried to escape but very few could make it. The few who were managed to escape returned to this profession again as their family did not accept them or did not find any other work to survive. So notion around virginity and their past experience of harassment leads them to adopt sex work as profession.

\subsection{Pull factors}

\subsubsection{Hope for better life}

Disaster hampers regular human life and in more severe way it snatches away everything from the affected people like, home, resource, livestock, livelihood source etc. disaster makes women's life more vulnerable when responsibility for adaptation is likely to fall on women including finding alternative way to feed their family, search shelter and new survival strategy during emergency period.

According to Parvin, (35) -

River erosion took away everything from us. While my elder brother denied taking any responsibility of the family my father's incomes were not sufficient for our family of 6 members. So to run a better life and to help my family I went to Dhaka."

While disaster causes huge destruction women want to turn around and change their vulnerable situation. Due to loss of resources, lack of income opportunity and situational causes women are forced to migrate to nearby cities for employment and live a better life. They want good food, good cloth or other basic needs to be fulfilled. So hope for better living or remove poverty women migrate to Dhaka while some are tempted to go into sex work.

\subsubsection{Rescue from violence}

In Bangladesh violence is very common phenomena in women's life. In addition to the general effects of natural disaster and challenges on women, rate of sexual and domestic violence against women and girls is increased after disaster which makes their life more miserable. Domestic violence highly prevails in society than other violence and it is harder for women to get rid of such violence due to family and social obligations.

In his regards a respondent Shila Akter said that-

"After disaster my family became very poor. They married me off with a man but he was addicted and tortured me every day for dowry. Day by day his torture was increasing. I had no way to come back to my father's family. They were already in problem and are not able to take my responsibility with a new born child. So when it goes beyond my tolerance level, to rescue myself from violence and poverty, I migrate to Dhaka with a neighbor woman who promised me to give garments job but she sold me to the agent of sex worker."

Violence in some cases pulls women to migrate and take risk in life to get rid of such situation. While violence increase after disaster and that triggers that as they have lost many things in disaster so they have nothing more to lose, moreover family responsibility, hunger and social instability instigate them more to migrate and forget previous miserable life.

\subsubsection{Hope of better work}

Most of the respondents said that they went to Dhaka to work in garments or as home maid. The reason they showed is that Dhaka is a rich city and would be easier to get job. They thought there is huge opportunity of work and can lead a good life. The agents of sex work who bring them in Dhaka showed the tempting offer of job mostly in garment. Very common temptation that they offer to the girls is to giving work in garment or in house as house servant. Thus the agents tempted village girl and brought to Dhaka and forced to adopt sex work as profession. In village, there is rear option of work for women. Patriarchal society does not allow women to work outside. In rural area this patriarchal attitude is stricter, so when women don't find any income generating work in village they used to migrate and many women trapped by agents and involved in sex work.

\subsubsection{Easy access and No investment}

Another pull factor which brings women into sex work mentioned by the respondents is this work or business does not require any capital or skill and women can easily access to this business. In other professions where women were being rejected by the society due to lack of skill or experience and they cannot start any business, because disaster affected women always face economic hardship, but in this profession they don't need any skill, experience or capital. Though in this profession no respondents came willingly, in this sex 
business all women are always fit if they are young. Youth and body are the main capital so when a woman migrates and forced to adopt sex work as profession finding no other option, they become engaged in sex work.

\subsubsection{Immediate Benefits}

Sex work gives few immediate benefits like money and shelter which may tempt vulnerable and destitute women to adopt this profession. Though sex work is prohibited and unacceptable profession in the society, but the destitute women who have lost home, resource or family and migrated to Dhaka in search of work to her survival is the most important issue. In FGD it came out that, while women do not find any work to earn money for food and shelter or the women who have been raped or victim of violence, to get immediate money and shelter they sometimes engage in sex work. The women enter into sex business immediately get a network and group so they no longer remain destitute or alone rather they get social protection by their network.

\section{CONCLUSION}

In light of the preceding discussion it is clear that disaster and migration do not affect all sections of people of the society equally, especially types of sufferings and consequences of these have gendered face which make women and men's coping up strategy different too. To explore the objective of the research, findings make it evident that disaster adds vulnerabilities on women due to some influencing reasons, therefore, some of them are forced to migrate to new areas and some are eventually involve in sex work. Some push and pull factors act as driving forces that lead them to sex work. Poverty, destruction of house, death of earning member, gender division of labor, job scarcity, demand of sex work, trap of agents, social stigma related with chastity, rape and sexual harassment, insufficient rehabilitation initiatives particularly focusing on affected women in time of disaster push them to sex work. On the other hand, hope for better life, better work, to rescue from violence, no investment and desire of immediate benefits also pull migrated women into sex work. The respondents mentioned it with grief, though no one came into this profession as first choice or willingly, therefore they could not leave this profession even if they wanted so extremely because there is very limited scope of work, near to zero, to return from sex work in normal life and people of the society would not accept them. So they are trapped here for their lifetime. This is not merely influencing only current generation of sex worker, but also confining their next generations too as they do not get access to the society even can't enjoy their basic human rights to come out from the vicious cycle of sex work like their mothers. The reasons to migrate after disaster and involve in sex work are multidimensional and intertwined with many issues. So collective and strategic initiatives should be taken by the all actors related with these sectors like Government, Non Government Organizations (NGOs), Disaster risk management authorities, migrant and sex worker's rights based organizations etc. The motive of this research was to explore the situation and draw attention of the respective parties so that related initiatives and policy can be made or existing policies can be changed to reduce women's vulnerable position in society. In order to do that some recommendation and realizations came out from this research findings such as- government should take immediate and sufficient initiatives after disaster to reduce and recover lose of disaster as much as possible. Rehabilitation programs should be reviewed and implemented considering gender dimensions and gendered impact of disasters. Necessary policy and program should be initiated and current ones should be reviewed to get better result. Creating more opportunity of income generating activities and skill development training for women can help to remove their poverty. Concern measures should be taken so that sexual harassment and violence do not increase after disaster and can fully be removed from the society as well. Current sex workers and their future generations should be given their basic, economic and health care rights, alternative work opportunity and relevant measures should be taken to rehabilitate them so that they can return into normal life. Awareness should be raised among people so that they can accept a sex worker as a human being and help them to return from this dark side of life. Last but not the least, necessary initiatives should be taken and eradicate the loopholes so that no more women are forced to come into this sector.

\section{REFERENCES}

[1] A. Shamsuddoha, and R, K. Chowdhury, Climate change impact and disaster vulnerabilities in the coastal areas of Bangladesh (COAST Trust, Dhaka, 2007)

[2] S. Khan, The Impact of Environment on Women's Health Status, in Jahan.et.al. (eds.), Environment and Development: Gender Perspectives (Dhaka: Women for Women, 1995)

[3] E. Enarson, Gender and Natural Disasters, IPCRR Working Paper Vol no.l (International Labor Organization Conference, 2000)

[4] M. Jahan, The impact of environmental degradation on women in Bangladesh: An Overview ( Dhaka: UPL, 2008)

[5] K. Hee-Kang, Analyzing the Gender Division of Labor: The Cases of the United States and South Korea, Asian Perspective, Vol. 33, No. 2, 2009, 181-229. 
[6] N. Ahmed, Environment, Development and Women: Bangladesh Perspective, in R. Jahan, et.al. (eds), Environment and Development : Gender Perspectives, (Dhaka : Women for Women, 1995)

[7] Y. Ahmed, Environmental Degradation and Natural Disasters: Who are the worst victims?, in I. Shamim, and K. Salahuddin, (eds.), Towards Beijing and beyond: Women Shaping Policies in Areas of Concern, ( Dhaka: Centre for Women and Children studies, 1995)

[8] J. Holandes, Climate change pushes poor women to prostitution dangerous-work, (Online; 2009) Available at: http://www.gmanews.tv/story/177346/climate-change-pushes-poor-women-to-prostitutiondangerous-work (Accessed date 19/12/2011)

[9] K. Bhasin, Understanding Gender, (New Delhi: Kali for Women, 2000)

[10] K. R. Kakumanu, and A. Lakshmanan, Gender and climate change adaptation in Tamil Nadu and Andhra Pradesh: a preliminary analysis (Delhi: 2010) (Online) Available at: change/climate-changeadaptation \&id=58995\&type=Document (Accessed on 20/12/2011)

[11] S. Harding, Feminism and Methodology (Bloomington: Indiana University Press, 1987)

[12] S. Harding, Rethinking Standpoint Epistemologies: What is strong objectivity, in A. Linda and P. Elizabeth, Feminist Epistemologies (NY: Routledge, 1993)

[13] M. S. Alam, Environmental Problems and Social Movements in Bangladesh, Social Science Review Vol. 16, No.2, 1999, 275-282.

[14] E. Shrader, and P. Delaney, Gender and Post-Disaster Reconstruction: The Case of Hurricane Mitch in Honduras and Nicaragua, World Bank Draft Report, 2000 (Online) Available at: http://www.anglia.ac.uk/geography/gdn/resources/reviewdraft.doc (Accessed on 20/12/2011)

[15] J. Williams, Unbending Gender (Oxford: Oxford University Press, 2000)

[16] D. Pearce, The Feminization of Poverty: Women, Work, and Welfare, Urban and Social Change Review, vol 11, 1978, 28-36

[17] S. Chant, Re-thinking the Feminization of Poverty in Relation to Aggregate Gender Indices, Journal of Human Development, vol.7, 2006, 201-220. 